\title{
SINTER PLANT WASTE HEAT RECOVERY PROCESS AND ITS BENEFIT IN INDIAN STEEL INDUSTRY
}

\author{
Priyabrata sahoo \\ Department of Mechanical Engineering, \\ Jharkhand Rai University, Ranchi, \\ Jharkhand, INDIA
}

\begin{abstract}
Sinter waste heat recovery system is a process onwards gainfully utilization of untapped waste heat from sinter plant for generating steam either for process steam requirement or in turn can produce power for plant. The saving in power will reduce the cost of production of sinter and in turn, the cost of steel. Sinter waste heat recovery is a very promising option for the future adoption in Indian steel industry. The current statuses of this technology in various countries are also under adoption. Finally, the potential of implementation in Indian steel has been discussed and its challenges as well as opportunities involved.
\end{abstract}

Keywords: Sinter waste heat recovery process, Reduction cost for sinter production, process steam generating from sinter waste, power from sinter waste.

\section{INTRODUCTION}

Control on climate changes and use of sustainable energy sources are real issues for global sustainability. The frequently used and most worrying thing now a day is global warming. This is actually increased of earth's average temperature due to greenhouse gases which trap heat that would otherwise escape from earth.

Further, industrialization and world population considered as two major factors to increase global steel and energy demand. World energy demand is continuously increasing due to increases these two factors. Amongst the different sources of energy (fossil fuels, wind, solar, hydro, geothermal and so on), fossil fuels still remain the most widely used. But recent studies specifying that waste heat produced from industries (large scale industries like steel making plants, oil refinery industries etc.) is more rapidly deteriorating the environment. To mitigate the demand, waste energy recovery and proper utilization of industrial waste presently looks an opportunity in primary energy reduction and improvement of energy

\author{
Prof. Om Prakash Satyam \\ Jharkhand Rai University, \\ Ranchi \\ Jharkhand, INDIA
}

efficiency for the global iron and steel industry. This paper develops an innovative study with respect to potential availability on waste heat recovery from straight line sinter plant in steel industry under Indian perspective and to quantify in terms of technical and economic potential.

\section{LITERATURE REVIEW}

Steel is produce from iron ore and scarp. The process involved for production of steel is known as steelmaking. In this steelmaking process impurities such as silicon phosphorus, sulfur and excess carbon are removed from raw iron. Alloying elements like manganese, nickel, chromium and vanadium are added to make different grades of alloy steel.

In steelmaking process dust and fumes are generated at many points in the process line of iron and steel. Fumes and dust are found in the steel preparation processes, especially in sintering, in front of the blast furnaces \& steel furnaces and in ingot making. Fine particles are being generated in the sinter during smelting and melting processes, when the molten iron comes in contact with air to form iron oxide. The waste generated by steel industry causes lot of environmental degradation.

Dusts and fumes from steel/metal making process not only create health hazard atmosphere but also create air pollution. Further, lots of sensible heats are being wasted in the form of cooling process through exhaust gases. Therefore, it is very important for the industries to look for the methods and ensures safe disposal/utilization of recycling of waste and recovery of waste heat.

Followings technologies are matured and utilized for the waste heat recovery in iron making process [1] 


\section{International Journal of Engineering Applied Sciences and Technology, 2021 Vol. 6, Issue 3, ISSN No. 2455-2143, Pages 167-171 \\ Published Online July 2021 in IJEAST (http://www.ijeast.com)}

Blast Furnace: TRT (Top Pressure Recovery Turbine); power is being generated utilizing the blast furnace gas pressure and temperature.

Coke oven: CDQ (cokes dry quenching system); steam and power is being generated through heat recovery from smothered red hot cokes

Sintering Plant: WHRS (waste heat recovery system); steam and power is being generated through heat recovery from sintered ore cooling process

In sinter plant during sinter cooling process lot of heat being carried away by the cooling air which is supplied by cooling fans from the bottom of cooler. This heat is being wasted. Hence, there is a tremendous possibility of gainfully utilization of this untapped waste heat for generating steam either for process steam requirement or in turn can produce power for plant and it will reduce the net power requirement for the plant [2]. The saving in power will reduce the cost of production of sinter and in turn, the cost of steel.

\section{ENERGY SYMMETRY IN INTEGRATED STEEL PLANT:}

Major energy source for steel making process are various fuels, steam and electrical power.

Approximately 90 to $94 \%$ of by product gases (like blast furnace gas, coke oven gas and LD gas) are being used for fuels. Around 6 to $10 \%$ of fuels (like coal, oil, natural gas etc.) are used. From used fuels around 47 to $53 \%$ are directly consumed in the steel production process and 50 to $53 \%$ are being utilized in power generation plant [5].

Around $90 \%$ to $95 \%$ of steam is generated through off gas heat recovery and remaining 5\% to $10 \%$ are generated through power generation process. However, $55 \%$ to $60 \%$ of the steam is being utilized in the production process and remaining $40 \%$ to $45 \%$ are being utilized for power generation purpose.

Considerably $70 \%$ to $73 \%$ of total energy are consuming during steelmaking process and consequently emitting large amount of exhaust energy. It is clear that there are ample of opportunity for saving of energy or heat recovery in iron making process.

\section{METHODOLOGY:}

\section{WASTE HEAT RECOVERY FROM SINTER PLANT}

The present study is regarding implementation of heat recovery technology in sinter plant on Indian perspective.

Sintering is an industrial process in the steel industry used to convert fine particles of iron ore into coarse grained iron known as sinter. In the process, fines of iron ore are mixed with other products such as coke fines and fired at a temperature below the melting point of the material. An important function of the sinter plant is to utilized waste iron-bearing materials to the blast furnace to produce iron.

Sintering machine agglomerates fine ores to make sinter that supplied to Blast furnace of integrated steel plant. Sinter cooler cools down the red hot sinter from the sintering machine by cooling air. The air, which becomes more than $300{ }^{\circ} \mathrm{C}$ by red hot sinter, is usually discharge into atmosphere with lots of sensible heat along with dust of the exhaust gas.

\section{Heat Recover Technology for Sintering Plant}

Sintering plant consists of two measure sections, sintering section and sinter cooling section.

Heat recovery from both parts has been developed by recovering heat from sintering section exhaust gas and from cooling section cooling gas.

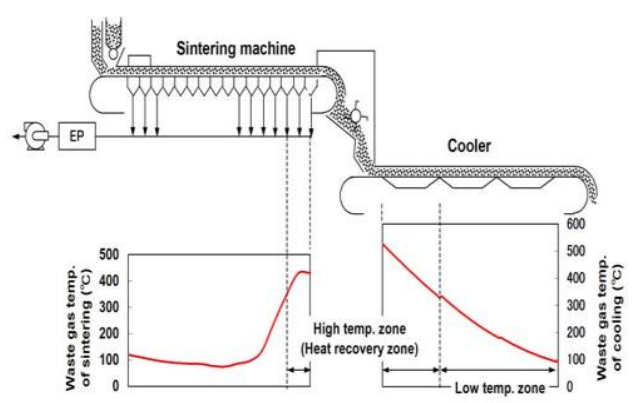

Gas temperature distribution has been shown in the above figure for both sections i.e sintering section and sinter cooling section. As indicated there is large temperature difference depending on the position of the section. Average gas temperature in both sections is in the level of $100^{\circ} \mathrm{C}-150^{\circ} \mathrm{C}$, too low for effective heat recovery.

However, heat recovery shall be limited to high gas temperature zone i.e. the final part of sintering section and primary part of cooling section, where $300{ }^{\circ} \mathrm{C}$ or higher gas temperature is available.

Though the area of heat recovery zone is limited but the gas volume of sintering process is large enough for useful heat recovery in commercial basis also.

\section{Configuration for Waste Gas Heat Recovery System and its Efficiency.}

Typical configuration of the waste gas energy recovery system has been shown in the above figure. The 
configuration consists of hood, dust catcher, heat recovery boiler, circulation fan and de-aerator.

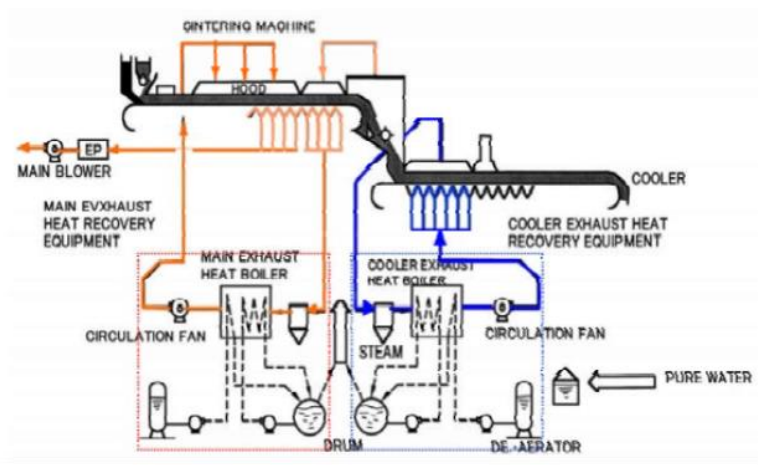

The exhaust gas emitted from Sintering machine is corrosive in nature and also contained some dusts. Recovery of heat is generally limited to high gas temperature zone as aggregated average temperature is low for heat recovery. Further, due to its corrosive nature, the gas temperature after heat recovery must kept above acid due point of the gas.

Atmosphere air used for Cooling gas is basically containing some dust. Same as sintering machine heat recovery, due to gas temperature distribution along with the cooler, heat recovery is limited to high gas temperature zone only.

Sintering machine exhaust gas heat recovery can be considered as two type i.e. circulation type and noncirculation type. In circulation type, gas are circulated to sintering machine after heat recovery as replacement of cooling gas, whereas in non-circulation type, the gas is lead to gas treatment facility directly after heat recovery. Circulation type is adopted in most cases to improve heat recover efficiency. above Fig. shows the combination of the sintering plant heat recovery system and cooler gas heat recovery.

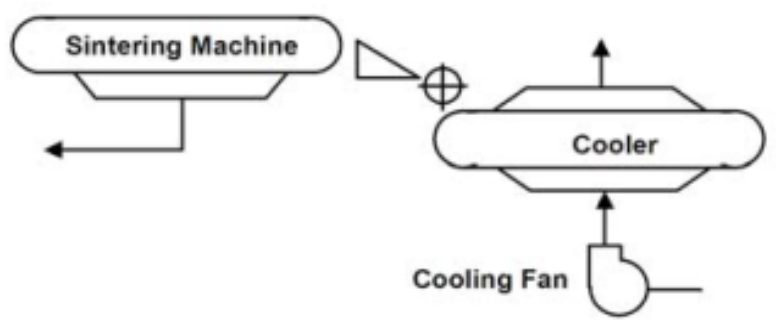

Case-1: Without WHRS

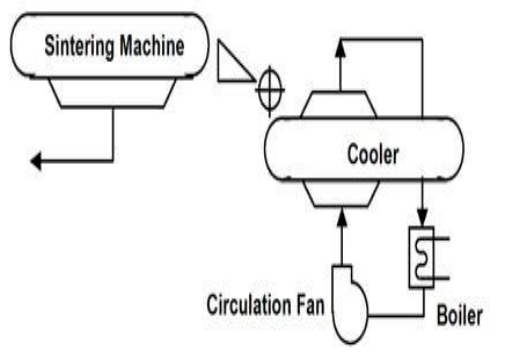

Case-2: Cooler WHRS

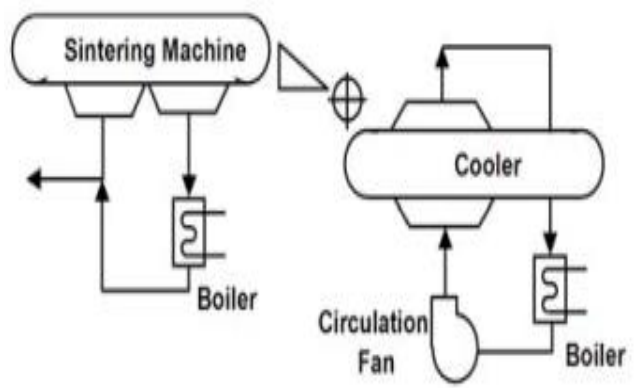

Case-3: Sinter \& Cooler WHRS

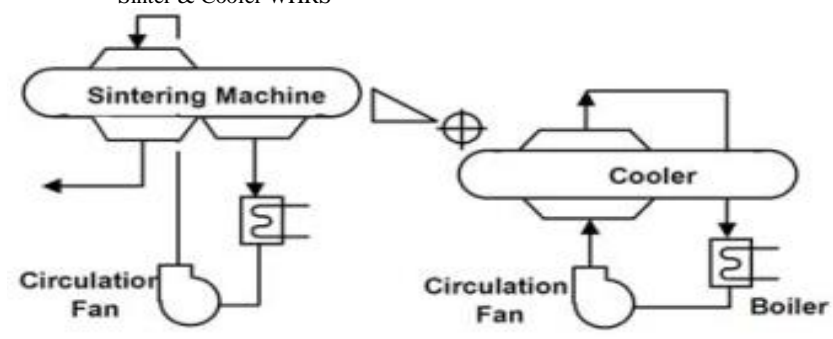

Case-4: Sinter \& Cooler Gas Circulation WHRS

On study it is found that input energy of sintering process is in the level of 145 to $150 \mathrm{MJ} / \mathrm{t}-\mathrm{Sinter}$. The heat source for sinter is solid fuel combustion such as cokes fine, blast furnace ash and etc. The effective thermal energy of the output thermal energy is approx. $38 \%$, which includes lime reaction heat, material moisture evaporation heat.

But around $48.5 \%$ Energy loss through off gas carry over which includes off gases from sinter machine and sinter cooler gas. 


\section{International Journal of Engineering Applied Sciences and Technology, 2021 \\ Vol. 6, Issue 3, ISSN No. 2455-2143, Pages 167-171 \\ Published Online July 2021 in IJEAST (http://www.ijeast.com)}

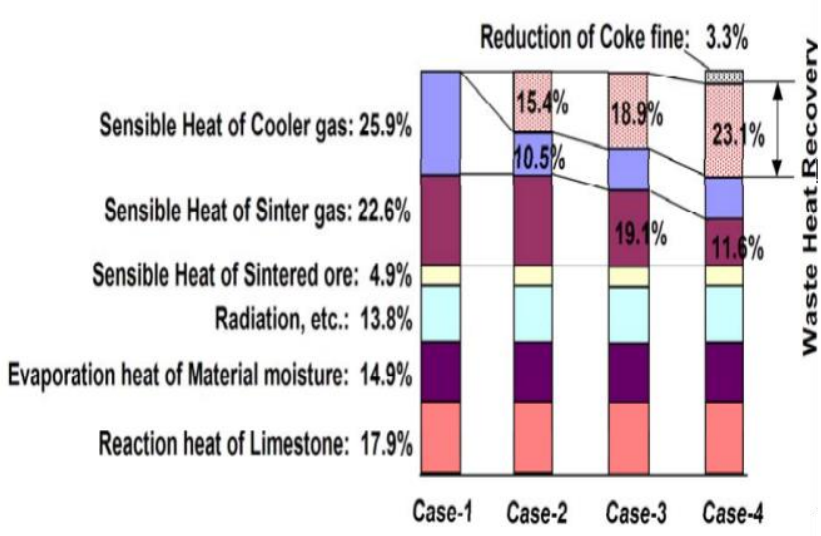

From above comparison chart it is clearly shows that WHRS effectively recycles massive amount of sensible heat from sintering plant gas i.e. from both sintering machine off gas and cooler gas.

Heat recovery of each case against case- 1 is compared hereunder;

Case-2 Cooler gas heat recovery (circulation) Cooling gas contains around $25.9 \%$ of the output thermal energy, within $60 \%$ is recovered.

Hence, around $15.4 \%$ of total output energy is being recovered.

Case-3 Cooler gas heat recovery (circulation) and sintering machine off gas heat recovery Sintering gas containing $22.6 \%$ of the total output thermal energy, within $15 \%$ is recovered. Together with $15.4 \%$ recovered from cooler gas, total $18.9 \%$ of off gas thermal energy is recovered.

Case-4 Cooler gas heat recovery (circulation) and sintering machine off gas heat recovery with gasrecirculation. Addition to case-3, sintering gas is circulated to sintering machine. $7.5 \%$ of the total output energy can be recovered. Also, coke breeze consumption can be decreased in the extent of $3.3 \%$ of the off gas total calorie.

\section{Sinter machine \& sinter cooler Gas Heat Recovery}

Hence, methods to enhance heat recovery system to existing sintering plant are introduced by heat recovery shall be highlighted considering maximum recover \& practicality of facility modification.

Sinter and Cooler gas heat recovery can be categorized in circulation type and non-circulation type.

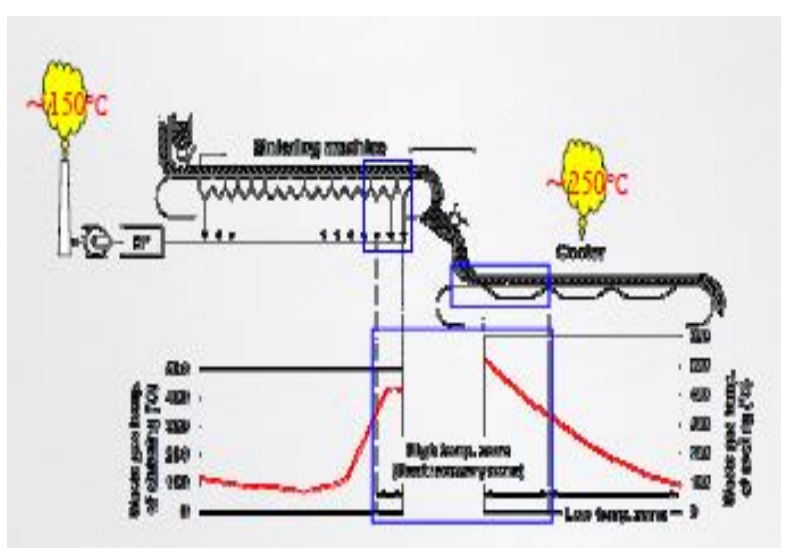

\section{Non-Circulation type}

After heat recovery from hot gas zone, cooling gas from both sections are emitted to atmosphere. As cooling gas temperature does not change with heat recovery system, cooling capability does not change before and after augmenting heat recovery system.

\section{Circulation type}

After heat recovery from hot gas zone, cooling gas from both sections is lead to cooler and reused for heating of sinter ore in sinter machine for proper combustion and sintered ore cooling. Cooler gas temperature rises through recirculation of gas which leads to higher heat recovery. On the other hand, cooling gas temperature rises up to the level of $180{ }^{\circ} \mathrm{C}$, cooling capability may decrease.

\section{CONCLUSION}

In steel industries of India this heat in sinter plant is normally wasted, if not tapped. Hence, there is a tremendous possibility of gainfully utilization of this untapped waste heat for generating steam, which in turn can produce power and it will reduce the net power requirement for the plant. The saving in power will reduce the cost of production of sinter and in turn, the cost of steel. Also, this can well meet the fan power required for sinter cooling and also, can supply excess power to other consumer.

However, recovered energy increases by $50 \%$ in circulation type compared to non-circulation type.

\section{REFERENCE}

[1] Charistopher Lloyd Williams (Dec 2015). A Waste Heat Recovery Strategy for An Integrated Steelworks. Doctoral thesis, Cardiff University 
[2] Aneke, Mathew (2012) Optimising thermal energy recovery, utilisation and management in the process industries. Doctoral thesis, Northumbria University. http://nrl.northumbria.ac.uk/10353/

[3] Bin ZHAO, Yuzhu ZHANG, Changqing HU \& Shibin WAN (2010) on their technical paper for Research on the Technology of Integrated Recovery and Collaborative Power generation for Sintering Dual Waste Heat Source.

[4] Teiji SHIBUYA, Hatsuki KUBO, Hideomi YANAKA and Hiroshi KURIHARA (1980) in Technical Report Transactions ISII, Vol.21, 1981 : implemented system for the recovery of Waste Heat from the Sinter plant which has medium-and-low potential now being executed at Keihin Works.

[5] Ramireddy. Pavankalyan Reddy1, Telukutla. Harika Sivani 2 (2014) International Journal for Research in Applied Science \& Engineering

Technology(IJRASET) on

Sinter Coolers.

[6] Energy Efficiency Improvement and Cost Saving Opportunities for the U.S. Iron and Steel Industry

An ENERGY STAR ${ }^{\circledR}$ Guide for Energy and Plant Managers by Ernst Worrell, Paul Blinde, Maarten Neelis, Eliane Blomen, and Eric Masanet

Published by Energy Analysis Department

Environmental Energy Technologies Division

Ernest Orlando Lawrence Berkeley National Laboratory University of California

Berkeley, CA 94720

October 2010 